\title{
9 Old and new forms of informal employment
}

\author{
Uma Rani
}

Until recently, informal labour was seen as a "transitory phenomenon" which would decline with economic development. However, informal labour continues to persist as a major form of work arrangement in the Global South and it has become increasingly prevalent in the Global North as well and is a growing concern. This chapter makes an attempt to outline the trajectories of old and new forms of informal labour in the Global South and in the Global North using the most recent data available. It also makes an attempt to identify the factors that seem to be driving these forms of informal labour.

\section{What do the data suggest?}

In the Global South, traditional forms of informal labour continue to persist. In most of the countries, over half of all workers are informally employed as ownaccount workers, casual day labourers, contract workers, industrial outworkers, homeworkers, without a clear employer-employee relationship, and they do not receive any labour and social protection from their employers. Indeed, just under half of the global workforce, both men and women, are self-employed (ILO 2018a; Bonnet, Vanek and Chen 2019). The past decade has seen some attempts at formalising the informal in the Global South but the approach and the results have been mixed, with some progress in some of the Latin American countries. Argentina, Brazil, the Dominican Republic, Ecuador and Uruguay reduced informal employment by more than 10 percentage points between 2002 and 2013. This was a result of the region's economic growth, and the formalisation strategies of legislations and incentives that were provided to both the workers and their employers (ILO 2014).

While in most of the Global South "informality" has always been the norm, today the trend is on the rise in the Global North, in the form of outsourcing, and flexible and temporary work. There has been an increasing trend of temporary employment (5.5 and 6.4 percentage points over the past two decades in the European Union and Canada) and part-time employment, which is involuntary in nature (two-fold increase in Spain and Slovakia over the past decade). Parttime work has not only grown in importance over the past decade but there has been diversification in its form, based on hours of work like "short part-time", 
"marginal part time" and "on-call work". "On-call” work, including zero-hour contracts, has brought variability and unpredictability to work and hours and is more prevalent in the service sector (transport, public administration and health), construction and agriculture. On average, 2.5 per cent of employees had "oncall" work in Europe and the highest incidence was recorded in the Netherlands and Slovenia in 2004 (ILO 2016a).

There has also been a rise in temporary agency work and other contractual relationships involving multiple parties over the past decades in the Global North and the largest markets for temporary work were the United States, Europe and Japan (ibid.). Similarly, since the 2008 global financial crisis, there has been a rise in "disguised employment" wherein employees are falsely classified as "independent" or "self-employed" and, therefore, do not enjoy their rights as an employee. In Slovenia, 3.6 per cent of the employed and in the US, about 8-13 per cent of the workers in the construction sector are "falsely self-employed" (ibid.). Finally, the past decade has observed the growth of the "on-demand" or "gig" economy, wherein digital platforms mediate work between firms, individual customers and a global or local pool of labour for a variety of tasks and services (crowd work platforms like AMT, Crowd Flower, Click Worker, UpWork, Microworkers; Task Rabbit; Uber; Zomato, domestic work apps such as Didi). These digital platforms can be classified as on-line web-based platforms and local app-based platforms (Berg et al. 2018). The characteristics of these workers resemble that of dependent workers, however, they are classified as "independent contractors" or "self-employed" or "freelancers" which has been contested and led to labour disputes (Cherry 2016). Some of the recent attempts to estimate the size of the online gig economy show that in the European Union between 1 and 5 per cent of the adult population have participated in the on-line platform economy for a paid task (Forde et al. 2017). Similarly, a study of 14 European countries shows that about 10 per cent of the adult population has provided labour services on platforms (Pesole et al. 2018).

These new forms of labour in the Global North resemble the informal labour of the Global South. However, there is also a rise of such labour in the Global South, which is largely undertaken by educated labour forces working in call centres and on digital platforms from home, which distinguishes them from the traditional informal labour, who possessed low levels of skills and had lower levels of education. These new forms of work do not provide minimum wages, workers' benefits, health insurance and pensions to workers. The tasks that these workers perform are quite varied and range from developing software architecture, applications, and algorithms to developing databases, web development, or product design to microtasks such as data collection, categorisation, tagging, transcriptions and content moderation. Most of the microtasks are geared towards developing databases for big firms, which have the potential of being used for automation or promoting products and services (Rani and Furrer 2019). Some of the tasks, such as content moderation, screening for scenes of obscenity, hate speech, war zone footage, abuse of children and of animals and more, have significant psychological impacts on the workers (Roberts 2016). Workers 
in India and the Philippines undertake a substantial proportion of such work, either in business processing outsourcing (BPOs) or on digital labour platforms.

The Global South has also observed a rise in informal work in formal firms, such as contractual and temporary work, which do not provide any protection to workers.

\section{What are the factors that drive these forms of employment?}

The development economists in the 1950s and 1960s were of the notion that the "traditional" or informal sector would disappear as development of industries would absorb the labour from this sector, based on the experience of Japan and some other European economies (Lewis 1954). However, the informal sector has not disappeared but instead has thrived in various forms since then and indeed it is part and parcel of the processes of industrialisation, development and globalisation.

The growth of the informal sector in the 1980s was due to the reorganisation of production systems from Fordist mass production towards "flexible specialisation" (Chen 2007; Piore and Sabel 1984). The dependence and interlinkages between the formal and informal sector, especially in the manufacturing process, helped to reduce the costs of formal manufacturing and distribution, thereby increasing the market competitiveness of formal firms (Castells and Portes 1989). Further, one could argue that in reciprocation, the workers and enterprises in the informal sector were able to upgrade their skills and technology through these linkages and improve their quality, efficiency and productivity. However, this was not sufficient for them to grow and integrate into the formal sector.

Further, increasing globalisation and pressures from it have also resulted in shifting the organisation strategies adopted by the firms, like sub-contracting and outsourcing. Due to global competition, firms hire core workers on informal work arrangements and outsource production and services to other small firms and countries. This has led to an increasing trend towards temporary, part-time and contract jobs, as well as industrial outwork, which has led to the erosion of income and benefits for the workers. Further, structural adjustment programmes in many parts of Africa, Asia and Central and Eastern European countries also resulted in the expansion of informal employment.

The countries in the Global North, especially Europe, have over the past decades observed partial deregulation, wherein they not only have implemented reforms liberalising the use of fixed-term contracts but also have allowed the growth of temporary and short-term contracts and diversified forms of part-time work. Further, the decline of unionisation and the regulatory role of collective bargaining have also been major factors in the rise in such forms of work. In both the Global North and the Global South there are worker protection laws but these are not widely implemented and enforced.

Technological developments and the rise of services have also led to increasing global integration in the past decades. A number of IT firms, including Amazon and Google, which used to perform most tasks in-house using permanent workers, 
are now outsourcing jobs to call centres, small firms and crowd-work platforms as tasks can be completed at a rapid pace using a global pool of labour. This is considered to be a new business model, called the new Taylorist production process, and is increasingly gaining popularity globally, as it reduces transaction costs, fosters productivity and employs a global pool of the most educated labour force. The global marketplace for digital piecework allows bidding and competition for rates and this, by design, drives the value of labour to the lowest global bidder, which further leads to the commodification of labour. By using a global labour force, this business model does not allow the workers to organise, as workers are dispersed and also are competing for jobs or "gigs": this is damaging working conditions and leading to unfair labour arrangements. Technology, rather than elevating the workers of the world in the twenty-first century, is actually helping business to reconfigure it in a way that leads to "a globalized race to the bottom in search of cheaper, faster and more human material sources in order for businesses to compete in a globalized 24/7 networked marketplace" (Roberts 2016: 44).

The recent global economic crisis has also brought economic uncertainty and, as a result, more workers have turned to informal self-employment and a number of enterprises have been adjusting through increases in temporary or casual work, on-call workers, and temporary reductions in working hours. Further, the new business model is said to be comprised of the "new augmented workforce", which includes a small proportion of workers on formal contracts, and the remaining are temporary workers, on-call workers, and digital platform workers (Deloitte 2017). Such business models would increase the trends towards further informalisation. In addition, new trends are also emerging wherein multinational companies are using street vendors to sell their produce without providing them with any labour protection. These trends are likely to continue to grow and, in the process, hinder current efforts towards formalisation. Governments have an important role to play in regulating platforms. In this context, the role of social dialogue is of the utmost importance to ensure that workers are protected. There have been some efforts at the national level, but much more needs to be done at both the national and international levels to ensure decent work for all. 